\title{
DEVELOPMENT AND FATE OF PORCINE GRAAFIAN FOLLICLES IDENTIFIED AT DIFFERENT STAGES OF THE OESTROUS CYCLE
}

\author{
R. H. F. HUNTER* AND T. G. BAKER $\dagger$ \\ School of Agriculture, and $\dagger$ Department of Obstetrics and Gynaecology, \\ University of Edinburgh
}

(Received 14th October 1974)

The concept that the oocyte plays a significant rôle in the regulation of follicular development in mammals is by no means new (Wilson, 1925), although the subsequent discovery of gonadotrophic hormones and their influence on the control of the Graafian follicle moved emphasis away from the notion of local interrelationships between the germinal and somatic components of the follicle. The concept has recently been reinvestigated (El-Fouly, Cook, Nekola \& Nalbandov, 1970) by the technique of 'ovectomy' (microsurgical removal of the oocyte from a Graafian follicle in vivo). These authors proposed that retention of the oocyte within the follicle inhibits luteinization of granulosa cells, whereas release of the oocyte by aspiration (or at ovulation) removes the local inhibition to luteal cell formation. While these observations excite considerable interest, a further series of experiments would seem to be necessary before a physiological interpretation is possible. In particular, the effect of surgical insults to the follicle on its developmental potential requires clarification. The present experiments were designed to answer this problem by examination of the effects of puncturing, scratching, or superficial pricking of follicles at various stages of the oestrous cycle. Such studies are a necessary prerequisite to experiments involving the effect of microsurgery on porcine follicles in organ culture (see Baker, Hunter \& Neal, 1974).

Mature Large White gilts or Large White $\times$ Landrace crosses, weighing 100 to $135 \mathrm{~kg}$ and aged approximately 6 to 8 months, were checked for oestrus once or twice daily in the presence of a mature boar. Eighteen gilts having 20- or 21-day oestrous cycles were subjected to surgery on known days of the cycle, the first day of oestrus being designated Day 0. Mid-ventral laparotomy was performed on Days 17 to 21 of the cycle under anaesthesia induced by an intravenous injection of Nembutal and maintained by closed-circuit halothane and oxygen. After carefully exposing the reproductive tract and displacing the fimbriae, the number and size of the follicles conspicuous on each ovary were recorded and, in some cases, photographed (Plate 1).

Follicles greater than 5 to $6 \mathrm{~mm}$ in diameter were either scratched with the bevelled edge of a 26-gauge intradermal needle and 'marked' with aqueous solutions of dyes (Cresyl blue, Janus green, or Phenol red), or the follicles were

* Address for all correspondence: School of Agriculture, West Mains Road, Edinburgh EH9 3JG. 
punctured with a similar needle and approximately $0.01 \mathrm{ml}$ dye was instilled into the follicle as a 'marker'. In eleven animals, such treatments were applied separately to the two ovaries or to individual pigs in order to avoid confusion between the results of scarification and puncturing. In a further two animals, Eagle's culture medium was instilled instead of the dye, while other follicles were pricked with a fine stainless steel needle without the introduction of fluid. Two to five follicles were treated in each ovary, leaving at least two large follicles unmarked. In five control animals, the ovaries were exposed, handled and examined closely, but the follicles were not scratched or punctured. After completion of the various treatments, which involved exposure of the ovaries for 2 to $5 \mathrm{~min}$, the fimbriae were replaced and the reproductive tract returned to the peritoneal cavity. The incision was sutured in three layers and the animals maintained in the post-operative area of the surgery until slaughter up to 6 days later. The reproductive tracts were excised at the abattoir immediately after completion of the bleeding and scalding procedures, and the ovaries were examined macroscopically and microscopically.

Table 1. Details of the number and distribution of Graafian follicles in eleven mature pigs subjected to microsurgical treatments during the follicular phase of the oestrous cycle

\begin{tabular}{|c|c|c|c|c|c|c|}
\hline \multirow{2}{*}{$\begin{array}{l}\text { Day of } \\
\text { oestrous } \\
\text { cycle }\end{array}$} & \multirow{2}{*}{$\begin{array}{l}\text { No. of } \\
\text { animals } \\
\text { treated }\end{array}$} & \multicolumn{4}{|c|}{ No. of Graafian follicles } & \multirow{2}{*}{$\begin{array}{l}\text { Macroscopic details of } \\
\text { punctured or pricked follicles }\end{array}$} \\
\hline & & Scratched & Ovulating & $\begin{array}{l}\text { Punctured } \\
\text { or } \\
\text { pricked }\end{array}$ & Ovulating & \\
\hline 17 & 2 & 5 & 5 & 6 & 0 & $\begin{array}{l}\text { Five had regressed. One follicle, } \\
\text { approximately } 12 \mathrm{~mm} \text { in diam., } \\
\text { was haemorrhagic. }\end{array}$ \\
\hline 18 & 2 & 4 & 4 & 8 & 1 & $\begin{array}{l}\text { Three were haemorrhagic cysts, } \\
\text { and four were enlarged follicles. }\end{array}$ \\
\hline 19 & 2 & 2 & 2 & 10 & 0 & $\begin{array}{l}\text { Three had regressed. The remainder } \\
\text { were large ( } 18 \text { to } 20 \mathrm{~mm} \text { ) cysts. }\end{array}$ \\
\hline 20 & 2 & 3 & $2^{*}$ & 5 & 0 & $\begin{array}{l}\text { Two had regressed. Three were } \\
\text { large }(20 \text { to } 22 \mathrm{~mm}) \text { cysts. }\end{array}$ \\
\hline 21 & 3 & 9 & $8^{*}$ & 8 & 1 & $\begin{array}{l}\text { Three haemorrhagic follicles, plus } \\
\text { four enlarged ( } 13 \text { to } 20 \mathrm{~mm} \text { ) follicles. }\end{array}$ \\
\hline Total & 11 & 23 & 21 & 37 & 2 & \\
\hline
\end{tabular}

* One follicle had not ovulated by the time of autopsy.

Slight capillary bleeding from the thecal layers to the surface of the follicles occurred consistently after scarification, while the puncturing procedure usually resulted in the loss of a little follicular fluid, and sometimes also of blood.

The results of the various treatments are summarized in Table 1 . The principal finding was that puncturing or pricking of large (6 to $9 \mathrm{~mm}$ diam.) follicles during the follicular phase of the oestrous cycle usually had a deleterious effect on their subsequent development. Thus, most $(73 \%)$ of the pricked or punctured follicles subsequently became either clear or haemorrhagic cysts, ranging in size from 11 to $22 \mathrm{~mm}$. An alternative sequel to these treatments, however, was 
PLATE 1

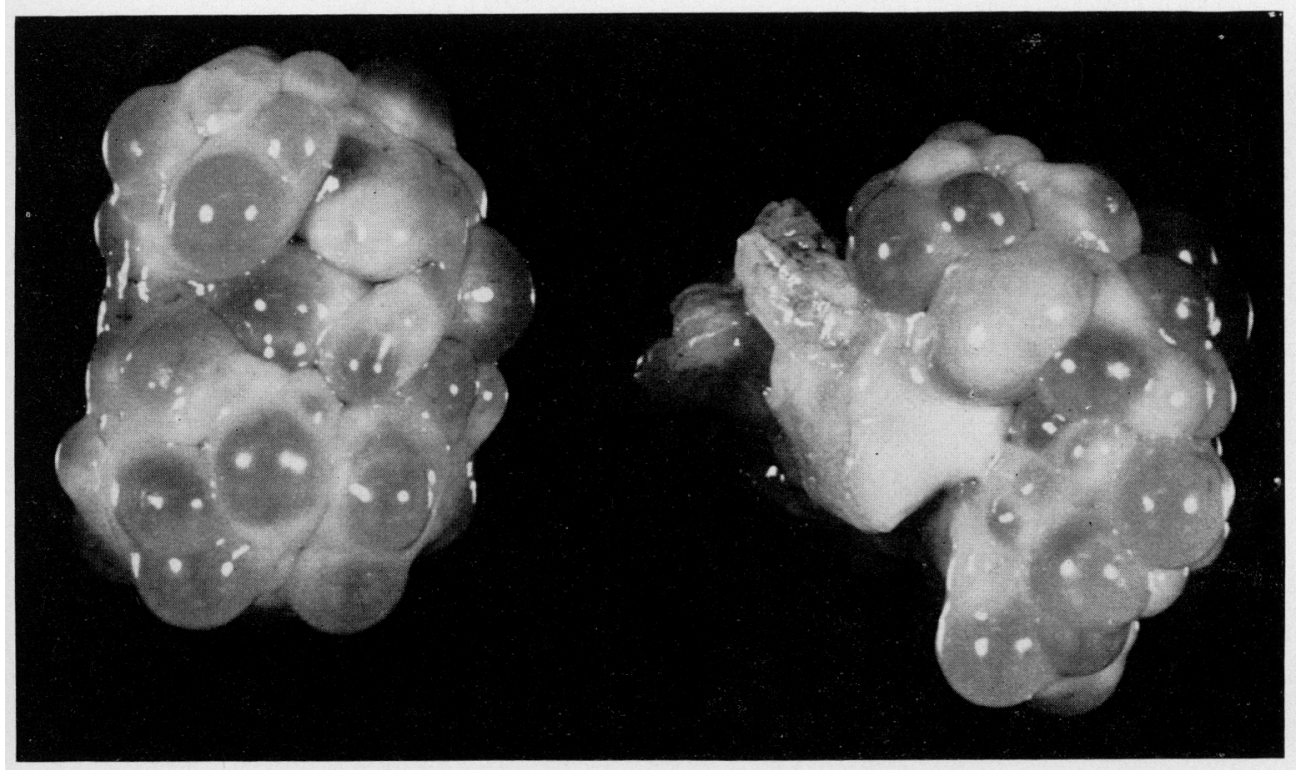

Ovaries photographed immediately upon removal from a gilt on Day 17 of the oestrous cycle. Note the large Graafian follicles, approximately 6 to $7 \mathrm{~mm}$ in diameter at this stage, which would undergo a significant reduction in number during the remaining days of the follicular phase.

(Facing p. 194) 
complete regression of the follicles down to colour-marked islands of tissue of 1 to $2 \mathrm{~mm}$ diameter. We gained the impression that puncturing early in the follicular phase (Day 17) induced the regression of the follicle, whereas treatment on Days 19 or 20 promoted the formation of cysts. Even when the follicles from oestrous animals were pricked or punctured, i.e. after the presumed LH surge, most of the follicles failed to ovulate and underwent enlargement. It is unlikely that the cystic condition could be attributed solely to the injection of the various aqueous dyes since the same effect was obtained with Eagle's culture medium, and also by pricking without the subsequent instillation of fluid.

By contrast, scratching and superficially marking the follicles with the dyes did not prevent the ensuing ovulation. Follicles scratched on Days 17 to 21 of the cycle were generally found $(91 \%)$ to have formed CL when examined at autopsy 6 days later. Examination of these CL within 2 days of ovulation revealed the presence of the colour 'marker' applied during scratching with the needle. Furthermore, a total of eighteen out of an expected twenty-two eggs were flushed from the oviducts of two animals, thus confirming that ovulation had occurred. Scarifying the surface of the follicles therefore had no detrimental effects; they behaved in a way similar to those merely handled and examined in the five control animals.

The results of the present study cast some doubt on the value of microinjection or aspiration procedures applied to pig follicles, if the normal process of follicular maturation and ovulation is not to be drastically disturbed. Nonetheless, our results on the formation of cysts agree closely with those of El-Fouly et al. (1970) after follicular puncture at a corresponding stage of the oestrous cycle, although their interpretation that "the ovum exerts a controlling rôle over the biosynthetic activity and morphology of follicles" is called into question. The fact that a small proportion of the colour-marked pricked and punctured follicles did ovulate leads us to conclude that the surgical insult can be variable in extent, and that the dyes in themselves did not prevent the normal maturation of the follicle. A local effect of surgical trauma in individual follicles has to be invoked rather than a systemic effect associated with endocrinological disturbance. The specific compartment of the follicle which responds adversely to the treatments has yet to be identified, but it may be related to a change in permeability which results in either changes in nutrition or oxygen tension affecting the germinal or somatic cells, or to a change in the concentrations of hormones in the follicular fluid (see McNatty, Sawers \& McNeilly, 1974).

The expenses incurred in this study were met by a grant from the Wellcome Trust, London, which is gratefully acknowledged. We also wish to thank $\mathrm{Mr}$ J. P. Hall and Mr M. Peet for technical assistance, and Mr A. Gardiner for supervision of the animals.

\section{REFERENCES}

Baker, T. G., Hunter, R. H. F. \& Neal, P. (1974) Studies on the maintenance of porcine Graafian follicles in organ culture. Experientia (in press).

EL-Fouly, M. A., Cook, B. \& Nalbandov, A. V. (1970) Changes in mature follicles of pigs following puncture or oocyte removal. Anat. Rec. 166, 302, Abstr. 
El-Fouly, M. A., Cook, B., Nekola, M. \& Nalbandov, A. V. (1970) Role of the ovum in follicular luteinization. Endocrinology, 87, 288-293.

McNatty, K. P., Sawers, R. S. \& McNeilly, A. S. (1974) A possible role for prolactin in control of steroid secretion by the human Graafian follicle. Nature, Lond. 250, 653-655.

Wruson, E. B. (1925) The Cell in Development and Heredity. Macmillan, New York. 